\title{
A Teaching Revolution and Practice for Cultivating Graduates in Design Sciences
}

\author{
ChengyuanRen $^{1, a}$, QianceSong ${ }^{2, b}$ \\ 1, 2 Tianjin Polytechnic University, Tianjin 300387,China \\ a, b15122643191@163.com
}

\begin{abstract}
Key words : teaching quality ; graduate education; teaching revolution;art designing science Abstract :Recently, it is a hot topic of graduate course teaching to enhance the research characteristic of teaching, and cultivate innovative ideation of graduates. We investigate the cultivation of high-quality graduates from the perspective of course teaching,with respect to the situation that the graduates majoring in design sciences in China lack of innovation. The paper presents our recent explorations and practice in research-oriented teaching of graduate courses and reports case studies with s courses for $\mathrm{PhD}$ students and master students. From the current situation analysis the problems in the teaching of design graduate courses, presented a series of reform measures. The feedback from students shows that the presented teaching revolution is useful for them to explore in a new research area, cultivate their team spirits, and improve their presentation skills, thus it helps to establish a solid foundation for their future academic life.
\end{abstract}

\section{Introduction}

With the development of economic globalization,Training high level personnel is increasingly becoming the focus of global education development,Postgraduate education as the elite education is one of the most important way of training high-level talents, The concept, mode and mechanism of graduate education must be one of the core contents of higher education.Especially in the domestic design science, There are all kinds of problems in the teaching system of postgraduate courses. We need to continue to research, in order to enhance the quality of postgraduate training.

\section{At this stage problems and current situation of the graduate course teaching}

Now in most universities of our country ,The teaching of graduate courses still adopt the teaching mode of similar undergraduate course, Basically followed the 'teacher speak, the students listen ' the traditional way of teaching ; The teaching content is relatively obsolete, and lack of the latest development ; In examination method, still use the traditional standardized test methods.So far, despite the absence of a uniform definition on innovative talents.But, it is generally believed that the innovative talents should have the following innovative thinking ability.It includes sensitivity, fluency, flexibility, originality and insightful.At present, the teaching mode of design graduate course in many colleges is not conducive to the cultivation of the innovation ability of graduate students. The specific performance is as follows:lack of critical scientific research needs;lack of potential to open up new areas;lack of search and evaluation capacity; It is not conducive to cultivate team spirit,lack of academic expression and communication capabilities.Therefore, how to improve the innovation ability of Design graduate is a major problem faced by graduate students.

\section{Teaching Reform Exploration and Practice of Design Graduate}

In the course of graduate education development, we need to solve the problem of the development of graduate education.At the same time, Graduate courses teaching problem involves more content and influence factors, both teaching itself, including the environmental factors that affect the teaching,We need to think from the overall perspective.The vast majority of postgraduates is creative motivation, they through years of learning for innovation have understanding, also hope to be able to produce new thinking in the process of learning and application practice, methods and 
theories, but these valuable innovation consciousness and for scientific inquiry spirit in the actual conduct of research, but the implementation is not enough, there is a greater contrast. Specifically, on the one hand, they showed the mental state of the active pursuit of innovation, in the understanding is very active, on the other hand they are acting up difficult to implement or much later in order to force the implementation, lack to join the courage and ability to practice.Thus combining the development of graduate education has been reformed to explore for a long time, we put forward measures to reform the following items.

\section{International communication}

Design graduate students need cutting-edge information resources,Creation premise is merged with the trend of the times.Many art and design institutions have in-depth study of all aspects of art and design education abroad.It includes curriculum, school system, teaching methods, teaching evaluation, combining production, employment guidance, Thereby drawing international advanced design concepts of art education and educational experience, and explore the road of culture with Chinese characteristics, art and design talents.

\section{Reform in teaching methods}

Teachers should guide stand point of view, the real subject is the students, under the theme of the framework provisions, students can give full play to imagination and creativity, active learning, and fully tap their creative thinking. How to train students' independent thinking and creative ability is the key to the study. Initiative to meet the needs of professional degree graduate education, curriculum adjustments, changes in teaching methods. Point to design postgraduate training is very clear, the goal is to cultivate a combination of theory and practice, having a design practice based, have a solid theoretical knowledge and scientific research ability, a pioneering and innovative spirit, outstanding scientific evaluation capacity design and artistic talents.

\section{Train the students' team spirit}

As a good designer, should have the consciousness of team, to participate in more projects, and display their talents. Especially under the trend of globalization, the partners have different countries, different cultural background, how to coordinate together to complete the task is new generation designers must master skills.

\section{To improve the level of the tutor team}

Role of instructors in imparting knowledge, improve operational mentor and visual culture is important link, through various channels, the tutor can understand where the disciplines in the strongest and most cutting-edge information, and can communicate with the strongest disciplines Professor, research cooperation, and was jointly organized by the international conference, in order to teach the outstanding graduate, so that strengthen the training of teachers.

\section{Reform of English Teaching}

English is a graduate must offer a course, to do graduate work in English teaching, with the university English four, six level of test scores, graduate entrance exam, etc. as the standard, does not meet the conditions to strengthen the basic knowledge of English learning, to meet the postgraduate examination and employment needs, so that students in the future can achieve excellent results.

\section{To participate in international competition and international conferences}

Project is practice, the market for the design level of inspection, take part in practical projects to 
enhance professional capacity-oriented, innovation and practical ability training as the focus, to encourage the construction of visualization, see the scale, heavy cross, seeking to share innovative practice school graduate base ; encourage new degree authorization complete creative and practical ability culture conditions. What companies are doing, what the demand, what we train; at the same time participate in the competition in the race, there will be design scholars around the world, graduate students were participating. This world, in internationally recognized outstanding work. International Conference is an effective way to learn to communicate, through international conferences, you can understand the current status of the international forefront of research in the field, compared to our current need to learn and supplement those. Through conferences may be good content of our study spread out, to be recognized in the international arena.

\section{Web interactive platform}

We should to support and improve a number of educational websites that have distinctive features, complete information and practical graduate education.It can demonstrate remarkable results disciplines, outstanding mentor team, design postgraduate education, expand graduate education influence.

\section{Improve the operation and management of teaching}

We will fully regulate the teaching curriculum, and formulate the measures for the implementation of teaching quality evaluation.On the other hand to increase the intensity of curriculum evaluation.And the focus of the new curriculum"postgraduate courses teaching excellence award" to declare the Curriculum Supervision and evaluation;Encourage graduate students to deepen the management of College Management,Conduct national scholarships, and school scholarships.And combined with the reform of the graduate education fees, and actively explore the optimization of the teaching environment.

\section{Summary}

To improve the quality of postgraduate training is a multi-party cooperation, continue to explore the process. It is not only the need for graduate students to give full play to their subjective initiative, also need to have a scientific curriculum system, the good campus environment and research atmosphere, but also inseparable from the scientific management of the guidance of the tutor's patience and school etc.. Only under the joint efforts of all parties, grasp each link of good graduate cultivation, efforts to forge ahead, constantly sum up experience and lessons, and actively explore innovative, in order to cultivate social needs that have both ability and political integrity of high-level professional personnel.

\section{References}

[1] Chen Yong,Qian Lv yang. Thinking and Countermeasures of the problems in the teaching of graduate courses[J]. Chinese Higher Medical Education, 2008,5:80- 87

[2] Zhang Xiaoli. Reflections on the teaching reform of graduate education based on the cultivation of scientific research ability [J]. Educational Exploration, 2010,7:36- 38

[3] Jing Jingshu, Wang Yukun,Liu Jian Wen . Research of colleges and universities students curriculum teaching reform study [J]. Science, Technology and Education, 2007,5:97- 99.

[4] Zhai Yajun, Ha MingHu.The students teaching problems and countermeasures [J].Chinese Higher Education Research. 2004,6:39- 41.

[5] Liu Guo fu, Li Hui, Zhang Qi, et al. Study on Journal of postgraduate teaching of higher education of [J].research, 2009,3:37- 38 
[6] in Zhonghai, Zhao Weifang. Research students course "research" weakening of attribution and improvement philosophy and strategy $[\mathrm{J}]$. Academic degrees and graduate students education. 2011, (04): 34-38.

[7] Jin Hongmei. Based on the re understanding of the significance of teaching graduate courses improvement ideas [J]. Academic degrees and graduate students education, 2008,9:37- 41. The annual worth of

[8] Liu Fei. The practice and exploration of the teaching reform of the graduate course [J]. Journal of Wuxi Institute of education, 2002,9:48- 50 